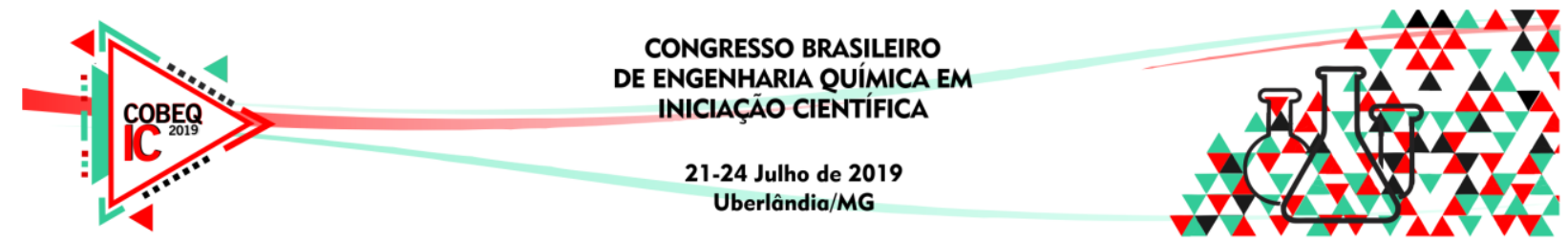

\title{
ESTUDO DA HIDRÓLISE ENZIMÁTICA DA LACTOSE EM LEITE PASTEURIZADO COM B-GALACTOSIDASES: KLUYVEROMYCES LACTIS E BACILLUS LICHENIFORMES.
}

\author{
J. M. Martins ${ }^{1}$, J. R. D. Finzer ${ }^{2}$ \\ ${ }^{1}$ Universidade de Uberaba, Faculdade de Engenharia Química \\ ${ }^{2}$ Universidade de Uberaba, Faculdade de Engenharia Química \\ E-mail para contato: jussarammartins@live.com
}

\begin{abstract}
RESUMO - Este estudo teve por objetivo estudar a hidrólise da lactose em leite pasteurizado utilizando as enzimas derivadas de Kluyveromyces lactis e Bacillus licheniformes. A hidrólise foi realizada a diferentes temperaturas $\left(10^{\circ} \mathrm{C} ; 34^{\circ} \mathrm{C}\right.$; $40^{\circ} \mathrm{C}$ e $55^{\circ} \mathrm{C}$ ), acompanhada por crioscopia até estabilização. Foram realizadas análise sensorial, físico-químicas e microbiológicas antes e após a hidrólise da lactose e análises pela Rede Brasileira de Laboratórios de Controle da Qualidade do Leite antes da pasteurização. A adição das enzimas provocou alterações nas propriedades físico-químicas do leite, diminuindo acidez, $\mathrm{pH}$, crioscopia, teores de gordura e lactose; aumentando densidade, extrato seco total (EST), extrato seco desengordurado (ESD) e proteína. A hidrólise da lactose possibilitou redução do teor de lactose para $1 \%(\mathrm{~m} / \mathrm{m})$. A enzima derivada de Bacillus licheniformes apresentou maior eficiência.
\end{abstract}

Palavras-chave: hidrólise da lactose, Kluyveromyces lactis, Bacillus licheniformes.

\section{INTRODUÇÃO}

A hidrólise enzimática é um dos métodos mais interessantes para a redução do teor de lactose no leite e seus derivados. Nele a enzima $\beta$-galactosidase, na forma livre ou na forma imobilizada, hidrolisa a ligação $\beta$ (1-4) da molécula de lactose, dando origem aos seus monômeros, glicose e galactose, (GEKAS E LOPEZ LEIVA, 1985).

Geralmente a quantidade de enzima a ser utilizada no processo é indicada pelo fornecedor. A temperatura ótima de ação da lactase é de $40^{\circ} \mathrm{C}$, esta temperatura também é ideal para o desenvolvimento de microrganismos no leite. Portanto, o tempo do processo nesta temperatura deve ser de no máximo 4 horas (LADERO et al., 2000; PROZYN, 2010).

Assim sendo e tendo em vista as informações relatadas, o objetivo desse trabalho foi avaliar a hidrólise enzimática da lactose em leite pasteurizado, empregando duas Bgalactosidades comerciais sob a influência de temperatura e concentração.

\section{MATERIAIS E MÉTODOS}




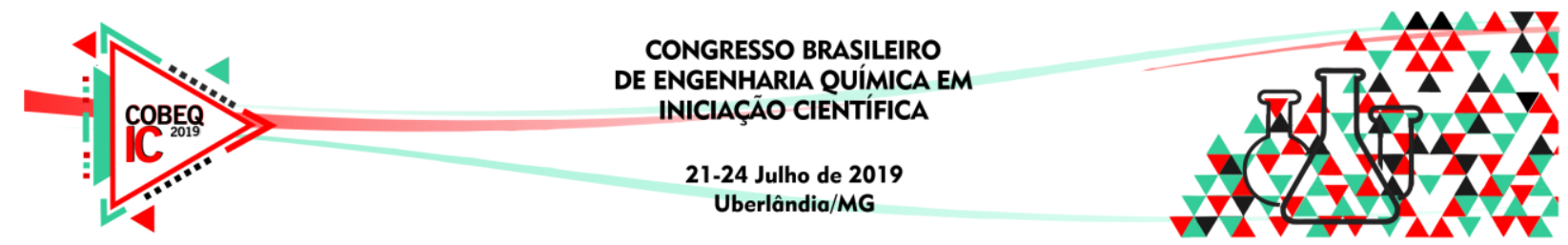

Para a realização deste estudo, foi utilizado leite cru cedido por produtor rural da cidade de Patrocínio - MG, que foi transportado para o Laboratório de Nutrição Animal da Faculdades Associadas de Uberaba - FAZU, onde a pasteurização.

As análises físico-químicas foram realizadas no leite antes e após hidrólise da lactose. Acidez total titulável foi determinada por meio de titulação com solução Dornic $(0,11 \mathrm{~N})$, (MAPA, 2013). A acidez titulável pode variar de 0,14 a 0,18 Dornic ( $\left.{ }^{\circ} \mathrm{D}\right)$; (MAPA, 2011). O $\mathrm{pH}$ foi determinado por medida direta com pHmetro digital, modelo PM 608. A gordura foi determinada com Ekomilk M. Extrato seco total (EST) no Ekomilk M. Índice Crioscópico foi determinado com ultrassom Ekomilk M, modelo Milkana KAM 98-2A da marca Cap Lab. A Densidade, proteína e lactose foram determinadas por lactodensímetro e Ekomilk M.

Análise de Escore de Autenticidade (EA) é uma exclusividade da ESALQ/USP e é válido em amostras de leite cru. Tem como objetivo de identificar possíveis adulterações no leite. O EA foi determinado antes da pasteurização na Clínica do Leite - ESALQ/USP. Os resíduos de antibiótico (ATB) no leite podem causar reações de hipersensibilidade, foi determinado na Clínica do Leite.

Os leites foram submetidos antes e após a etapa de hidrólise as seguintes análises sensoriais: Aspecto e Cor: líquido branco, ou ligeiramente amarelado, homogêneo e sem partículas/substâncias estranhas; Sabor e Odor: ausência de sabores/odores estranhos.

Foram utilizadas duas enzimas $\beta$-galactosidases derivadas de Kluyveromyces lactis (Maxilact ${ }^{\circledR}$ LGi 5000) e Bacillus licheniformes (Lactlow L). A hidrólise da lactose foi realizada adicionando-se $0,24 \mathrm{~g}$ da enzima $\beta$-galactosidase em alíquotas de $300 \mathrm{~mL}$ de leite pasteurizado (CAMPOS, et al.), totalizando quatro amostras. Cada uma delas foi incubada em uma das temperaturas: $10^{\circ} \mathrm{C}, 34^{\circ} \mathrm{C}, 40{ }^{\circ} \mathrm{C}$ e $55^{\circ} \mathrm{C}$.

O acompanhamento da hidrólise da lactose foi feito através de análise de crioscopia, em intervalos de 1 hora. Foi feita uma estimativa da porcentagem de hidrólise, utilizando-se a Equação 1, recomendada por empresa fornecedora da enzima (LONGO, 2006).

$\%$ de Hidrólisealcançada $=350,877 \times($ Crioscopia final $)-\frac{(\text { Crioscopia inicial })}{0,00285}$

\section{RESULTADOS E DISCUSSÕES}

\subsection{Análises feitas pela RBQL}

As análises realizadas no leite cru antes da etapa de pasteurização apresentaram resultados de Escore de Autenticidade (EA) de 2,12 (normal <5) e Resíduo de antibiótico (ATB) negativo, não existindo presença de antibiótico.

\subsection{Análises microbiológicas}

Na Tabela 1, são descritos os resultados obtidos. 


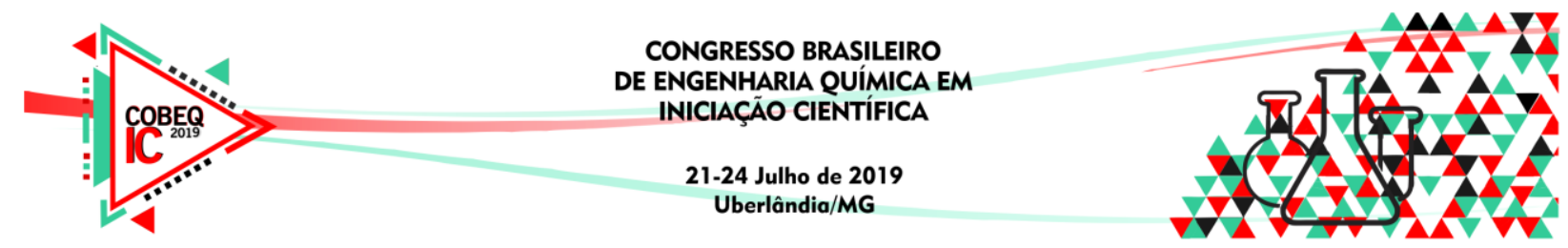

Tabela 1 - Resultado das análises microbiológicas

\begin{tabular}{|c|c|c|c|}
\hline Parâmetro & Enzima & Matéria-prima & Leite após a hidrólise \\
\hline \hline $\begin{array}{c}\text { Contagem de células } \\
\text { somáticas (CCS) } \\
(\mathrm{x} 1000 \text { células/mL) }\end{array}$ & $\begin{array}{c}\text { Bacillus licheniformes } \\
\text { Kluyveromyces lactis }\end{array}$ & 345.00 & 512.00 \\
\hline $\begin{array}{c}\text { Contagem bacteriana } \\
\text { total }(\mathrm{CBT}) \\
(\mathrm{x} 1000 \mathrm{UFC} / \mathrm{mL})\end{array}$ & $\begin{array}{c}\text { Bacillus licheniformes } \\
\text { Kluyveromyces lactis }\end{array}$ & 80.00 & 106.00 \\
\hline
\end{tabular}

Em 2014 foi publicada pelo MAPA a IN-62 onde os limites de CCS e CBT, são de 100 mil UFC/mL para CBT e 400 mil céls/mL para CCS. Nota-se que com a utilização da enzima derivada de Bacillus licheniformes, os resultados ficaram ligeiramente fora dos parâmetros. Essa enzima apresenta temperatura ótima a $40^{\circ} \mathrm{C}$. Segundo Longo (2006) $40^{\circ} \mathrm{C}$, é a temperatura ideal para proliferação de microrganismos patogênicos no leite, e o tempo de reação não deve ultrapassar 4 horas, e no experimento, as amostras ficaram submetidas a temperatura de 34 e $40^{\circ} \mathrm{C}$ por 6 horas, o que explica o aumento de contagem total.

\subsection{Análises sensoriais}

Tabela 1 - Resultado das análises sensoriais.

\begin{tabular}{|c|c|c|}
\hline Parâmetro & Matéria-prima & $\begin{array}{c}\text { Leite após a } \\
\text { hidrólise }\end{array}$ \\
\hline \hline Aspecto & Líquido branco & Liquido branco \\
\hline Cor & Normal & Normal \\
\hline Sabor & Ausência & Ausência \\
\hline Odor & Ausência & Ausência \\
\hline
\end{tabular}

\subsection{Análises físico-químicas}

Na Tabela 2, são descritos os resultados obtidos das análises microbiológicas que foram realizadas antes e após a etapa de hidrólise no leite.

Tabela 3 - Parâmetros físico-químicos das matérias-primas e das amostras após a reação de hidrólise.

\begin{tabular}{|c|c|c|c|}
\hline Parâmetro & Enzima (lactase) & $\begin{array}{c}\text { Matéria- } \\
\text { prima }\end{array}$ & $\begin{array}{c}\text { Leite após } \\
\text { a hidrólise }\end{array}$ \\
\hline \multirow{2}{*}{ Acidez $\left({ }^{\circ} \mathrm{D}\right)$} & $\begin{array}{c}\text { Bacillus licheniformes } \\
\text { Kluyveromyces lactis }\end{array}$ & 16 & $\begin{array}{c}17 \\
16.8\end{array}$ \\
\hline
\end{tabular}




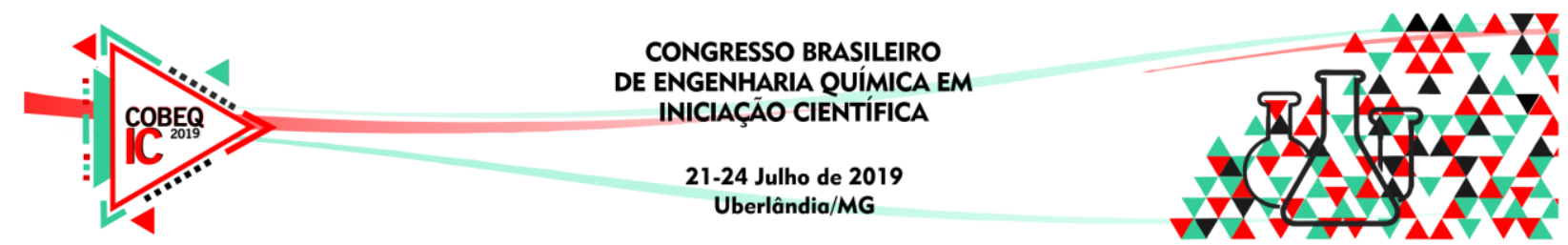

\begin{tabular}{|c|c|c|c|}
\hline $\mathrm{pH}$ & $\begin{array}{c}\text { Bacillus licheniformes } \\
\text { Kluyveromyces lactis }\end{array}$ & 6.66 & $\begin{array}{l}6.61 \\
6.63 \\
\end{array}$ \\
\hline $\begin{array}{l}\text { Gordura } \\
(\% \mathrm{~m} / \mathrm{m})\end{array}$ & $\begin{array}{l}\text { Bacillus licheniformes } \\
\text { Kluyveromyces lactis }\end{array}$ & 4.17 & $\begin{array}{l}3.36 \\
3.96\end{array}$ \\
\hline $\begin{array}{l}\text { Densidade } \\
(\mathrm{g} / \mathrm{mL})\end{array}$ & $\begin{array}{l}\text { Bacillus licheniformes } \\
\text { Kluyveromyces lactis }\end{array}$ & 1031.00 & $\begin{array}{l}1043.00 \\
1037.80\end{array}$ \\
\hline $\operatorname{EST}(\% \mathrm{~m} / \mathrm{m})$ & $\begin{array}{l}\text { Bacillus licheniformes } \\
\text { Kluyveromyces lactis }\end{array}$ & 12.78 & $\begin{array}{l}15.11 \\
13.45\end{array}$ \\
\hline $\begin{array}{c}\mathrm{ESD} \\
(\% \mathrm{~m} / \mathrm{m})\end{array}$ & $\begin{array}{l}\text { Bacillus licheniformes } \\
\text { Kluyveromyces lactis }\end{array}$ & 8.61 & $\begin{array}{l}11.75 \\
9.49\end{array}$ \\
\hline $\begin{array}{l}\text { Proteína } \\
(\% \mathrm{~m} / \mathrm{m})\end{array}$ & $\begin{array}{l}\text { Bacillus licheniformes } \\
\text { Kluyveromyces lactis }\end{array}$ & 3.35 & $\begin{array}{l}3.43 \\
4.09\end{array}$ \\
\hline $\begin{array}{l}\text { Crioscopia } \\
\quad\left({ }^{\circ} \mathrm{C}\right)\end{array}$ & $\begin{array}{l}\text { Bacillus licheniformes } \\
\text { Kluyveromyces lactis }\end{array}$ & $-0,488$ & $\begin{array}{l}-0.685 \\
-0.570\end{array}$ \\
\hline $\begin{array}{l}\text { Lactose } \\
(\% \mathrm{~m} / \mathrm{m})\end{array}$ & $\begin{array}{l}\text { Bacillus licheniformes } \\
\text { Kluyveromyces lactis }\end{array}$ & 4.37 & $\begin{array}{l}1.11 \\
1.20\end{array}$ \\
\hline $\mathrm{ST}(\% \mathrm{~m} / \mathrm{m})$ & $\begin{array}{l}\text { Bacillus licheniformes } \\
\text { Kluyveromyces lactis }\end{array}$ & 12.78 & $\begin{array}{l}14.1 \\
13.6\end{array}$ \\
\hline
\end{tabular}

Após a hidrólise observou-se uma ligeira elevação da acidez do leite com a utilização das duas enzimas diferentes, mesmo assim os leites permaneceram dentro dos padrões estabelecidos pelo MAPA para leites pasteurizados. $\mathrm{O} \mathrm{pH}$ das amostras submetidas a hidrólise também apresentaram redução, mas se mantiveram dentro dos parâmetros estabelecidos. Esse aumento da acidez e redução do $\mathrm{pH}$ ocorre devido à atividade dos microrganismos presentes no leite, principalmente às bactérias láticas, que promovem acidificação (TREVISAN, 2008).

Verificou-se a diminuição da gordura onde ela foi maior com o uso da enzima derivada de Bacillus licheniformes. Não se encontrou na literatura, justificativa para a redução da gordura. Obteve-se um aumento da densidade das amostras após a etapa de hidrólise. A 


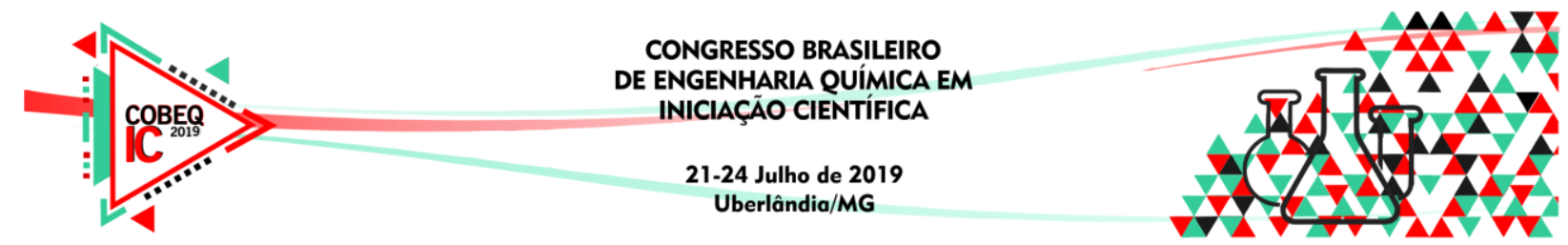

utilização da enzima lactase ( $\beta$-galactosidase) ocasiona modificações físicas e químicas no leite (TREVISAN, 2008).

Obteve-se redução no índice crioscópico de 0,197 utilizando a enzima derivada de Bacillus licheniformes e de 0,82 utilizando a enzima derivada de Kluyveromyces lactis. Esta redução deve-se ao fato de que com a hidrólise ocorre um aumento dos açúcares redutores do leite, que passa a apresentar, além da lactose, glicose e galactose resultantes da reação. Com isto aumenta a concentração dos constituintes solúveis na solução leite (TREVISAN, 2008).

\subsection{Hidrólise enzimática da lactose}

As amostras foram submetidas à etapa de hidrólise onde houve acompanhamento da hidrólise da lactose que foi feito através de análise de crioscopia, realizada em intervalos de 1 hora. Com os valores encontrados de crioscopia, calculou-se através da Equação 1, recomendada por um dos fabricantes, a hidrólise estimada, a qual a média dos tratamentos foi $70 \%$ com enzima Bacillus licheniformes e $29 \%$ com a utilização da enzima Kluyveromices lactis. A partir daí calculou-se a lactose estimada como podemos ver nas Figuras 1 e 2.

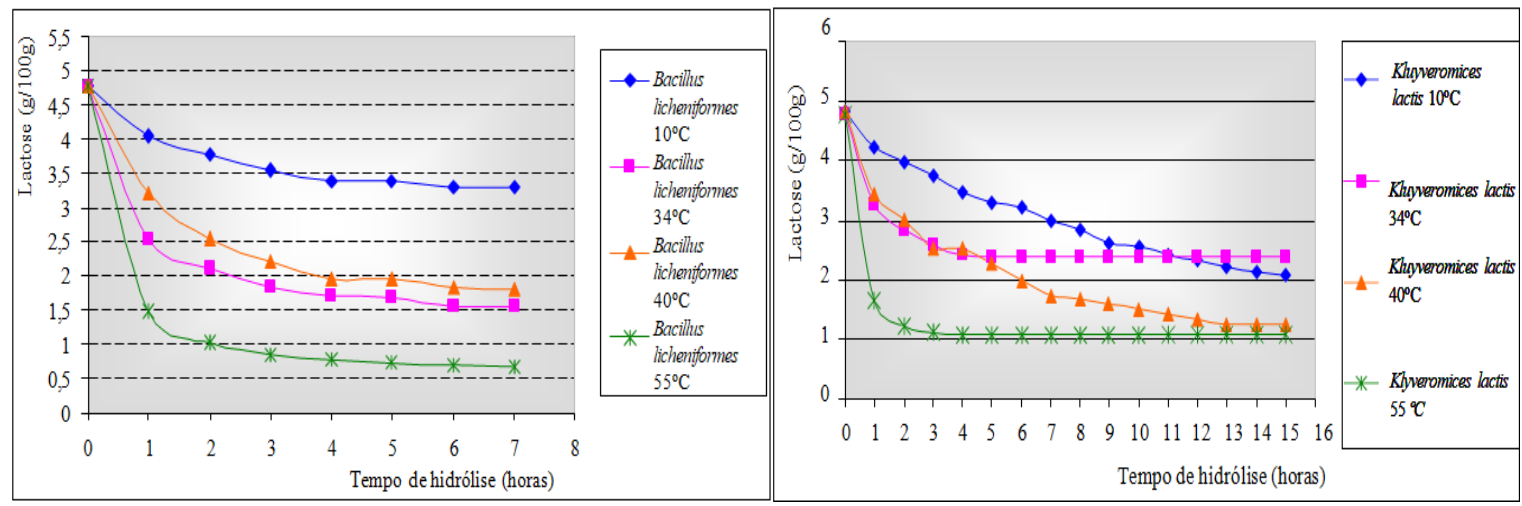

Figura 1e 2. Curvas de hidrólise Bacillus licheniformes e Kluyveromyces lactis.

Nota-se, na Figura 1, que as curvas de hidrólise foram diferentes nas amostras incubadas a $10^{\circ} \mathrm{C}, 34^{\circ} \mathrm{C}, 40{ }^{\circ} \mathrm{C}$ e $55^{\circ} \mathrm{C}$, mas todas atingiram o grau de hidrólise com aproximadamente 3 horas de incubação. Além disso, segundo a marca Lactlow apresenta maior faixa de $\mathrm{pH}$ de atuação de 4,2 a 9,0, o que torna a enzima ideal para produtos lácteos de maior acidez.

Nota-se, na Figura 2, que as curvas de hidrólise foram semelhantes nas amostras incubadas a 10 e $34{ }^{\circ} \mathrm{C}$. Na temperatura de $40^{\circ} \mathrm{C}$ houve uma melhor eficiência de hidrólise da lactose nos tempos 3,5 e 4 horas de incubação, explicado pelo fato que a temperatura ótima de ação da enzima derivada de Kluyveromyces lactis proporciona maior atividade a $40^{\circ} \mathrm{C}$.

\section{CONCLUSÕES}

Conclui-se com o estudo realizado que a aplicação das enzimas derivadas de Bacillus licheniformes e enzima derivada de Kluyveromyces lactis, alteraram propriedades físico- 


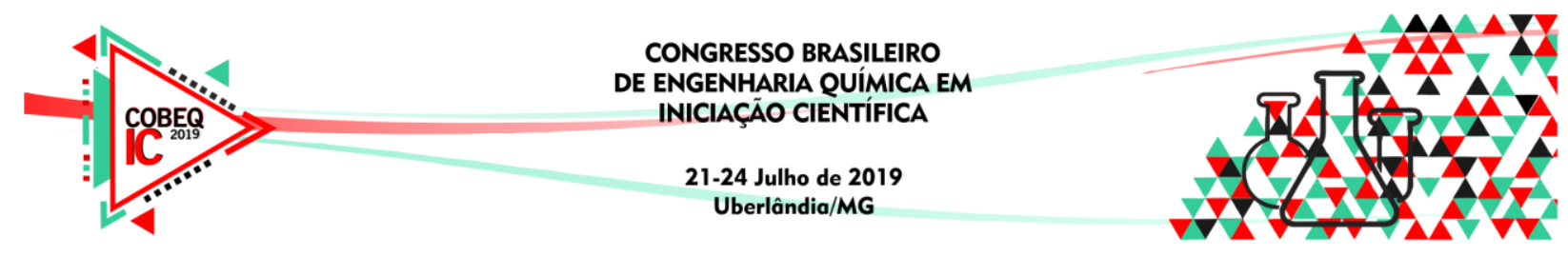

químicas no leite após a etapa de hidrólise. Obteve-se diminuição da acidez, pH, crioscopia, teores de gordura e lactose e aumento na densidade, extrato seco total (EST), extrato seco desengordurado (ESD), e teores de proteína.

Obteve-se parâmetros de escore de autenticidade (EU), resíduos de antibióticos (ATB) e análise sensoriais dentro do especificado pela legislação. O CCS e CBT afeta diretamente o valor industrial do leite e características de qualidade sensorial (sabor), e essa característica não sofreu alteração após a hidrólise do leite.

Ambas as enzimas apresentaram eficiência na redução do teor de lactose, sendo mais significativo o resultado onde foi do Bacillus licheniformes.

Observou-se também que a velocidade de hidrólise na temperatura de $10^{\circ} \mathrm{C}$ foi menor, que comparada às outras temperaturas que próximas da temperatura ideal das enzimas.

Obteve-se teores de lactose de $70 \%$ para a enzima derivada de Bacillus licheniformes e $29 \%$ para enzima de Kluyveromyces lactis.

\section{REFERÊNCIAS BIBLIOGRÁFICAS}

GEKAS, V.; LOPEZ-LEIVA, M. Hydrolysis of lactose: A literature review. Process Biochemistry, Amsterdam, v. 20, n. 2, p. 2-12, 1985.

CAMPOS TCAS, D’ALMEIDA WK, et al. UNOPAR Cient., Ciênc. Biol. Saúde. 2009; 11(4):51-4

LADERO, M.; SANTOS, A.; GARCIAOCHOA, F. Kinetic modeling of lactose hydrolysis with an immobilized $\beta$-galactosidase from Kluyveromyces fragilis. Enzyme and Microbial Technology, v. 27, n. 8, p. 583-592, 2000.

MINISTÉRIO DA AGRICULTURA, PECUÁRIA E ABASTECIMENTO (MAPA). Determinação de acidez titulável em leite fluido. Código: MET POA/10/01/01, Páginas 4. Emissão: 22/04/2013.

TREVISAN, A. P. Influência de diferentes concentrações de enzimas lactase e temperaturas sobre a hidrólise da lactose em leite pasteurizado. Dissertação (Mestrado). Programa de Pós-Graduação em Ciência e Tecnologia de Alimentos, Universidade Federal de Santa Maria, Santa Maria, RS, 2008. 